\title{
LEY PENAL Y HECHO PUNIBLE EN EL CODIGO PENAL PERUANO DE 1991
}

Felipe Villavicencio Terreros

La reforma penal peruana de la década de los años ochenta está caracterizada por el reemplazo de la marcada influencia del Código Penal Tipo para Latinoamérica que se observa en los proyectos de código penal de setiembre y octubre de 1984, agosto de 1985 y abril de 1986, para luego recepcionar la influencia de la reforma penal de Brasil, España, Alemania, Portugal, Austria, Argentina y otras, como se observa en los siguientes proyectos de setiembre de 1989, julio de 1990 y enero de 1991.

A nuestro entender, la necesidad de reemplazar la influencia positivista por ideas más cercanas a la interpretación criminológica de una sociedad pluralista en conflicto como la nuestra, fundamenta los intentos para sustituir al Código Penal de 1924, de clara influencia en el proyecto suizo de Stoss.

\section{TITULO PRELIMINAR}

Finalidad preventiva.- La primera impresión de nuestro artículo I del Título Preliminar es que abandona el criterio retributivo para acogerse al preventivo, pero en este punto debe resaltarse que la función preventiva que se señala no se fija sólo como medio protector de la sociedad, como ocurre con el artículo III del Título Preliminar de la Propuesta Alternativa Española de 1982, sino que además la concibe como medio protector de la "persona humana", colocándola incluso en primer lugar. Además, debe tomarse en cuenta otras disposiciones ne sólo de nuestro Código Penal, sino también de la Constitución y de otras leyes, como la de Ejecución Penal (Decreto Legislativo 654). Dentro de ellas resulta destacable el artículo IX del Título Preliminar de nuestro Código Penal, por lo que es conveniente tomar en cuenta 
nuestro comentario a dicha norma, pero como conclusión podría esbozarse la idea de que la orientación político-criminal de nuestro código se acoge a un criterio preventivo.

Recuérdese que estamos analizando la función que se establece en el Derecho positivo (el prisma de la dogmática jurídica) y no cuál debe ser ésta (el punto de vista filosófico-jurídico).

Principio de legalidad.- El artículo II del Título Preliminar se refiere al principio de legalidad. La fuente principal del Derecho Penal es la ley penal; se suele afirmar que es la única fuente formal, directa o inmediata del Derecho Penal, pero no es exacto. "Es cierto únicamente, que en virtud del principio de legalidad de los delitos y las penas, sólo pueden crearse figuras delictivas y establecerse o agravarse penas mediante una ley. Son también fuentes del Derecho Penal, la costumbre, los principios generales del Derecho y los tratados internacionales que se hayan incorporado al ordenamiento jurídico interno"(1).

La Constitución de 1979 establece el principio de legalidad en el artículo 2 inciso 20 d): "Nadie será procesado ni condenado por acto u omisión que al tiempo de cometerse no esté previamente calificado en la ley, de manera expresa e inequívoca, como infracción punible, ni sancionado con pena no prevista en la ley" (Este principio tiene su complemento en el principio de reserva - artículo 2 inciso 20 a) Constitución).

En la legislación penal peruana, aparecía este principio en el Código Penal de 1863 (artículo 1) y luego en los tres primeros artículos del Código Penal de 1924.

Prohibición de analogía.- La analogía puede ser entendida como el proceso por el cual son resueltos los casos no previstos por la ley, extendiéndoles a ellos las disposiciones previstas para casos semejantes (analogía legis) o están deducidos de los principios generales del derecho (analogía juris) (2).

(1) Cerezo 1988, pág. 153.

(2) Mantovani 1979, pág. 103. 1988, pág. 105. 
La prohibición de la analogía (artículo III del Título Preliminar del Código Penal de 1991) sólo se aplica a la analogía perjudicial para el inculpado (analogía in malam partem), es decir, aquella que extiende los efectos de la punibilidad. Por el contrario, la analogía favorable (analogía in bonam partem) es aceptada (3), a través de los procesos de interpretación de la ley penal. Por ejemplo: interpretación que extienda analógicamente circunstancias atenuantes o causales personales de exclusión o cancelación de la punibilidad (v.gr. artículo 208 del Código Penal).

Principio de lesividad.- En la actualidad, el concepto de bien jurídico está siendo fundamentado en una orientación político-criminal y en su desarrollo se pueden observar conceptos jurídicos y constitucionales.

El concepto constitucional de bien jurídico entiende que la Constitución es la que fija la orientación básica para limitar la función punitiva estatal. En este sentido existen dos funciones: quienes otorgan a la Constitución un carácter genérico y las que toman a la Constitución en sentido estricto en relación a las específicas instituciones que la integran (4).

El concepto sociológico de bien jurídico busca definirlo otorgándole un contenido social. Una tendencia centra su atención en el perjuicio social, pero prescinde de toda consideración individual cuya base teórica parte del funcionalismo. Esta posición llega a una total formalización social del problema, como una función inmanente al sistema (5).

El artículo V del Título Preliminar del Código Penal de 1991 se refiere al principio de lesividad, indicando que la pena necesariamente precisa de la lesión o puesta en peligro de bienes jurídicos tutelados por la ley.

Garantía jurisdiccional.- El artículo V del Título Preliminar del Código no acepta la existencia de la llamada justicia paralela o popular que se presenta en nuestro pais. Nuestra Constitución prohíbe toda forma de justicia paralela (artículo 233 inciso 1) con excepción de la arbitral y militar.

(3) Cf. Batista 1984, pág. 117. Mirabete 1988, pág. 52.

(4) En sentido constitucional vid. Roxin 1976, pág. 21. Rudolphi 1975, pág. 332. Berdugo 1984 pág. 308.

(5) Bustos 1984, pág. 59. 
"Esta concepción de una justicia unitaria es evidente para una idiosincrasia europea moderna, mas no para Estados con fuertes derechos consuetudinarios locales y étnicos y sistemas informales de justicia" (6).

De acuerdo al principio o garantía de ejecución penal no existe pena sin un régimen legal que lo precise, sin tratamiento ni resocialización (artículo VI del Título Preliminar).

En el Perú, "el régimen penitenciario tiene por objeto la reeducación, rehabilitación y reincorporación del penado a la sociedad, de acuerdo con el Código de Ejecución Penal" (artículo 234, $2^{\circ}$ párrafo, Constitución).

Responsabilidad penal.- En el artículo VII del Título Preliminar se regula lo que en doctrina se denomina el principio de responsabilidad o "culpabilidad". Recuérdese que algunos prefieren usar el término "responsabilidad" al de "culpabilidad" para evitar cualquier vinculación con el criterio retributivo, aun cuando otros consideran esto innecesario, pues la culpabilidad se puede fundar en criterios preventivos (7). De cualquier manera, el legislador peruano abandona la redacción de los proyectos de agosto de 1985 (artículo IV) y de abril de 1986 (artículo IV): "No hay hecho punible sin culpabilidad. La ley penal prescribe toda forma de responsabilidad objetiva"; acogiendo la actual, dejando de lado una disposición muy comprometida con los criterios retributivos.

Límites de penas y medidas.- Si bien el sistema dualista está cuestionado y se aboga por un sistema monista en cuanto a las consecuencias jurídicas, debe tenerse en claro que dicho monismo no se concibe en el sentido de reconocer tan sólo a la pena o, por el contrario, sólo a las medidas de seguridad, sino en el sentido de otorgar a ambas la misma función (así, quien otorgue a la pena la función de prevención especial, abandonará el sistema de la doble vía, acogiendo el sistema vicarial).

Así, nuestra norma establece que la pena es proporcional a la responsabilidad por el hecho (La exposición de motivos del Código Penal al referirse a dicha norma expresa: "proporcionalidad de la pena a la responsabilidad por

(6) Brandt 1987, pág. 42.

(7) En este sentido Muñoz Conde y Mir Puig. 
el hecho") (8), mientras que la medida de seguridad es proporcional a los intereses públicos predominantes (artículo VIII del Título Preliminar).

Función preventiva de penas y medidas.- El artículo IX del Título Preliminar tiene como antecedente lo dispuesto en los proyectos de agosto de 1985 (artículo VIII) y de abril de 1986 (artículo VIII), cuyos textos expresaban: "Las penas tienen función preventiva, protectora, retributiva y resocializadora. Las medidas de seguridad persiguen fines de curación y rehabilitación". Con lo que se plasmaba una teoría unitaria aditiva en cuanto a la pena (9). Velásquez, al comentar el artículo VIII del proyecto de abril de 1986, afirma que "pareciera afiliarse a una concepción mixta o teorías de la unión, pues se alude a la función preventiva (prevención general y especial), protectora (prevención general y especial) retributiva (retribución) y resocializadora (prevención especial)", y preventiva especial en cuanto a las medidas de seguridad. La versión del Código de 1991 abandonó la referencia a la retribución (mantenida de manera contradictoria en la exposición de motivos).

Aplicación extensiva.- Creemos que el artículo $\mathrm{X}$ del Título Preliminar efectivamente se trata de una pauta interpretativa (10) y no de un principio elevado por el legislador al nivel de principio rector.

Aquí, se expresa que las reglas de la parte general (Libro Primero) se aplican a las leyes penales especiales. Otro problema es el determinar cuáles son las lcyes especiales que han quedado vigentes y cuáles han sido derogadas (total o parcialmente) por el Código Penal de 1991.

\section{LA LEY PENAL}

Principio de territorialidad.- Fundado en el criterio de la soberanía del Estado, la ley penal tiene validez estrictamente en el territorio de la República, sobre las infracciones cometidas por cualquier persona, sin importar la nacionalidad del autor y los partícipes (artículo 1 del Código Penal de 1991).

( 8) Publicación oficial. Diario "El Peruano", pág. 6.

(9) Velásquez en ADP 1988, pág. 37.

(10)Idem. 
Entendemos por territorio al suelo, subsuelo, dominio marítimo y espacio aéreo que los cubre (artículo 97 de la Constitución). Es pues, todo lugar donde se ejerce la soberanía del Estado (11).

El principio del Pabellón (derecho de bandera) es una ampliación del principio de territorialidad por el que se extiende la aplicación de la ley penal peruana a hechos punibles cometidos en naves o aeronaves nacionales públicas y en las naves o aeronaves nacionales privadas, que se encuentren en alta mar o en espacio aéreo donde ningún Estado ejerza soberanía.

Principio de personalidad activa, en el sentido que la ley peruana se aplica al nacional que cometa una infracción en el extranjero (artículo 2, inciso 4, del Código Penal). Se exige que la infracción sea susceptible de extradición, haya doble incriminación (delito también punible en el Estado extranjero) y cuando el culpable entrare de cualquier manera en la República. La nacionalidad de la víctima es indiferente.

Principio de personalidad pasiva, en el sentido que la ley peruana se aplica al extranjero que comete un delito contra un nacional fuera del territorio de la República (artículo 2, inciso 4, del Código Penal). Se exige que la infracción sea susceptible de extradición según la ley peruana, haya doble incriminación, y cuando el culpable ingresare de cualquier modo en el territorio de la República.

Lugar de comisión del delito; cuando la acción y el resultado del delito se producen en un mismo lugar de comisión, no se presenta dificultad para los efectos de la territorialidad. Sin embargo, la más importante dificultad se encuentra en los delitos a distancia que son aquéllos en los que la conducta tiene lugar en un territorio y el resultado en otro. La teoría de la ubicuidad (Binding) considera que el lugar de comisión es tanto el de la acción como el del resultado. Esta es la posición más prestigiosa y la que es incorporada en códigos recientes (12).

(11) Jescheck I, pág. 209.

(12) Código Penal de Portugal, 1982, artículo 7; Código Penal de Austria, 1974, artículo 67. 
En la doctrina nacional, Bramont (13) se inclina por esta teoría. Hurtado Pozo también lo hace, pero en sentido restringido (14). Consideramos que la solución más aceptable es la de la teoria de la ubicuidad, que es la regla que el artículo 5 del Código Penal de 1991 adopta ("El lugar de comisión de un delito es aquél en el cual el autor o partícipe ha actuado u omitido la obligación de actuar o en el que se producen sus efectos").

Una de las garantías que origina el principio de legalidad es que la ley penal es irretroactiva (artículo 187 de la Constitución). La irretroactividad supone que la ley penal sólo es aplicable a los hechos cometidos después de su puesta en vigencia.

Precisamos que este principio de irretroactividad de la ley penal se refiere a la ley penal más grave, pues existe la retroactividad de la ley más favorable (artículos 187, 233 inciso 7, de la Constitución; artículo 6 del Código Penal).

\section{EL HECHO PUNIBLE}

Las infracciones penales se clasifican formalmente en delitos y faltas (artículo 11 del Código Penal de 1991). Esta es la clasificación bipartita. En el Derecho comparado existe una clasificación tripartita que identifica crimen, delito y contravención. En el Perú no existe la diferencia entre crimen y delito.

Las diferencias entre delito y falta son esencialmente cuantitativas o legales. El propósito de señalar diferencias cualitativas no ha tenido éxito (15).

Delito culposo.- El tipo de lo injusto del delito culposo requiere que la conducta afecte el deber de cuidado y se verifique un resultado (en los delitos culposos con resultado).

(13) Bramont 1978, pág. 199.

(14) Hurtado Pozo 1987, pág. 215, 216.

(15) Jesús 1985, pág.163. Cerezo 1987, pág. 257. 
El aspecto fundamental de los delitos culposos es la afectación al deber de cuidado. Es obvio que la falta de cuidado se ubica en relación a la vida social en situaciones concretas y surge del ordenamiento jurídico. Por tanto, se trata de un concepto objetivo y normativo.

Este concepto de deber de cuidado no puede ser general sino sólo el que le incumbe al autor individual.

Es importante observar el resultado en los delitos culposos de resultado, pues se presenta como su límite típico. Como hemos expresado, no cualquier violación al deber de cuidado es delito culposo. Se exige un resultado típico previsto en el Código Penal (muerte de una persona, artículo $111 \mathrm{del}$ Código Penal; lesión, artículo 124 del Código Penal). El resultado integra el tipo. No es una condición objetiva de punibilidad como piensan algunos. Encontrándose dentro del tipo, su función es conceder relevancia jurídico-penal a la infracción de la norma de cuidado (16). La razón de exigir el resultado de lege ferenda, puede justificarse como una garantía de seguridad para los ciudadanos. Esta función limitadora está orientada en uı sentido político criminal positivo (17).

El delito omisivo.- En el campo típico, el legislador prohíbe conductas de dos maneras: cuando el tipo describe la conducta que prohíbe (estructura comisiva) y cuando el tipo prohíbe conductas diferentes a las que describe (estructura omisiva). Negamos la posibilidad y la necesariedad de un superconcepto de acción (omnicomprensivo) que incluya a la acción y a la omisión (18).

Delito de omisión propia.- La omisión está tipificada exprẹsamente. Sólo son punibles si están previstas en el Código Penal. Ejemplo: Omisión de prestar auxilio inmediato (artículo 127 del Código Penal), omisión legal de actos oficiales (artículo 377 del Código Penal), omisión de prestación de auxilio, cometida por el policía (artículo 378 del Código Penal).

Delito de omisión impropia.- Es la omisión no tipificada expresamente

(16) Mir Puig 1983, pág. 82.

(17) Idem.

(18) Huerta Tocildo 1982, pág. 255. 
en el Código Penal y su penalidad se origina sobre la base de la interpretación, que realiza el juez, de un delito comisivo que admite estructuras omisivas. Ejemplo: El salvavidas que intencionalmente omite rescatar a un enemigo, quien circunstancialmente se está ahogando. Esta omisión es impropia y debe discutirse en el tipo de homicidio (artículo 106 del Código Penal). Es precisamente a la fórmula de la omisión impropia a la que se refiere el artículo 13 del nuevo Código Penal.

La doctrina reconoce que el tipo objetivo de los delitos impropios de omisión es semejante al de los propios, con dos importantes particularidades: la causalidad y la posición de garante del autor que no está establecida expresamente en la ley. Se reconoce que todos los delitos comisivos pueden ser practicados por omisión, excluyéndose sólo aquéllos cuya acción típica supone necesariamente un comportamiento activo (19), delitos de propia mano (20).

Un tratamiento especial merece la problemática de la causalidad en los delitos de omisión impropia. Es evidente que en los delitos omisivos la conducta distinta de la ordenada no causa el resultado. No se puede exigir la causalidad física. En estos delitos no existe esa causalidad física.

El delito de omisión impropia es siempre un delito especial propio, es decir, se exige un deber especial del sujeto con el bien jurídico, lo que se ha llamado posición de garante. Esta posición de garante no es una característica exclusiva de la autoría de los delitos de omisión pues, en los delitos (omisión propia) en los que se exige evitar un resultado, el omitente también es garante, sólo que el tipo legal describe la omisión y determina en qué condición concurre la posición del deber (21).

Este deber de impedir el resultado sólo puede ser un deber jurídico, pues no basta el simple deber moral, como erróneamente indica el inciso 1 del artículo 13 del Código Penal.

En este sentido, las fuentes del deber de garante pueden organizarse en

(19) Fragoso 1985, pág. 242.

(20) Bacigalupo: Delitos impropios de omisión, pág. 137.

(21) Goessel 1984, pág. 54. 
dos grupos: deber de protección de un bien juridico y deber de vigilancia de una fuente de peligro.

Deber de protección de un bien jurídico.- En estos casos, el omitente tiene el deber de protección de un determinado bien jurídico. Esto se debe a que, en general o en ciertas situaciones, algunas personas no están en condiciones de proteger sus bienes jurídicos, por lo que existen otras personas que tienen una relación de defensa con ellos.

Pueden distinguirse distintas situaciones:

Relaciones familiares.- El deber de garante en base a relaciones familiares puede originarse en normas jurídicas. Pero, en realidad, las relaciones familiares de cuidado sólo pueden precisarse en cada caso concreto. No es suficiente el carácter legal-formal, sino que será necesario exigir que la relación familiar de cuidado exista realmente.

Relaciones de comunidad.- Se trata de los casos más discutidos. Se refiere a la participación voluntaria de varias personas en una situación de peligro que genera un deber de socorro mutuo; es decir, varias personas que están tácitamente obligadas a socorrerse entre sí.

Aceptación voluntaria.- En este supuesto una persona deposita su confianza en otra y esta última la acepta. Se exige que exista una decisiva dependencia de quien acepta la protección y quien la recibe. En este sentido, no es posible fundar la responsabilidad en casos en que la persona protegida corra peligros mayores o deje de tomar precauciones. Muchos incluyen en esta parte la idea del contrato para limitar las características de la aceptación voluntaria. Mediante el contrato el sujeto acepta un deber de garantía en favor de otra persona. Ejemplo: la enfermera que acepta un contrato para la atención nocturna de un enfermo. También, el salvavidas contratado en las piscinas publicas, las maestras contratadas para el cuidado de los niños menores, etc.

Deber de vigilancia de una fuente de peligro.- Esta segunda categoría de deberes supone que el sujeto ha otorgado o asumido una garantía de seguridad respecto de una fuente de peligro que tiene bajo su control. Esta fuente puede ser originada por una conducta anterior del mismo sujeto (hecho precedente), puede surgir del ámbito de su dominio material, o puede tratarse de peligros creados por terceras personas. Hecho precedente (injerencia).- 
Es una de las fuentes más antiguas del deber de garante. Según ésta, quien ha creado con su conducta precedente una situación de peligro, para un bien jurídico, tiene el deber de evitar que el peligro se convierta en lesión. Ambito de dominio.- Comprende los deberes de garante que emanan de quien posee el dominio de una fuente de peligro. Ejemplo: los responsables de construcciones que generen peligro, los dueños de animales, los responsables de industrias peligrosas (minas u otras excavaciones de recursos naturales). Conducta de terceras personas.- Se trata de los sujetos que tienen el deber de vigilar las conductas de otras personas. Ellos asumen posición de garante respecto de las conductas vigiladas, de los daños que estos terceros puedan causar. Ejemplo: El deber de vigilancia de los hijos menores por parte de sus padres (artículos 287 y 418 del Código Civil).

En los delitos de omisión propia también se puede sancionar la conducta culposa. Al igual que en los delitos culposos de omisión, el acento se ubica en la infracción al deber de cuidado objetivo. En los delitos de omisión impropia creemos también posible se presente la falta de cuidado debido, en relación al deber de garante del sujeto.

Error de tipo (ausencia del dolo).- El artículo 14 primer párrafo del Código Penal de 1991 se refiere a esta figura; es el error o ignorancia sobre uno o todos los elementos que integran el tipo objetivo. El error de tipo excluye el dolo.

Existe error de tipo evitable, cuando el agente, observando el cuidado debido, pudo haber salido del error en el que se encontraba y pudo evitar el resultado. En estos casos sólo se sanciona si existe un equivalente tipo culposo. Por el contrario, es error de tipo inevitable cuando el agente, habiendo observado el cuidado debido, no pudo salir del error en el que se encontraba, originando el resultado. En este caso, la conducta debe ser atípica aunque exista un tipo culposo.

El Código Penal actual adopta esta solución. Error de tipo vencible: la infracción será castigada como culposa si se hallare prevista en la ley. El error invencible excluye la responsabilidad o la agravación (art. 14 del Código Penal).

Error de prohibición.- El artículo 14 (segundo párrafo) del nuevo Código introduce la figura del error de prohibición y con ello zanja la polémica 
entre la teoría del dolo y sus variantes, y la teoría de la culpabilidad, inclinándose a favor de esta última.

Para determinar la vencibilidad en el error de tipo basta comprobar que el sujeto no actuó con el debido cuidado; por el contrario, para determinar la vencibilidad en el error de prohibición son necesarias más exigencias, pues son más las opciones del sujeto para salir de ese error. En consecuencia, en un error de prohibición no es suficiente que se haya actuado cuidadosamente (en el sentido del deber de cuidado de los delitos culposos) para que dicho error sea considerado invencible.

Dadas las características del juicio sobre la vencibilidad de un error de prohibición, y sus diferencias con el juicio de vencibilidad de un error de tipo, resulta razonable que el legislador peruano haya indicado consecuencias penales diferentes: al error de prohibición vencible se atenúa la pena, en tanto que al error de tipo vencible le corresponde la figura del delito culposo cuando se hallare previsto como tal en la ley (artículo 14, $1^{\text {er }}$ párrafo del Código Penal).

Tentativa.- Se distingue entre tentativa inacabada y tentativa acabada. La diferencia entre tentativa acabada e inacabada debe resolverse tomando en consideración la representación del autor en base a su plan de acción individual. Normalmente, basta recurrir a la subjetividad del autor, pero en algunos casos el criterio objetivo puede dar buenos resultados, lo que es una consecuencia de la extensión del criterio objetivo-individual.

Tentativa inacabada.- Se presenta cuando según el plan del autor éste debería realizar sucesivos hechos para lograr el fin al que dirige su acción, pero no logra realizarlos pues se presenta una interrupción originada en la intervención voluntaria del mismo agente (desistimiento, artículo 18 del Código Penal) o en circunstancias externas.

Tentativa acabada.- Se presenta cuando el agente, según su plan personal, ha realizado todos los actos necesarios para que se consume el delito, faltando sólo la producción del resultado. Es decir, desde el punto de vista del autor, él ha realizado todo lo necesario para que el delito se consume. Sin embargo, el resultado no se produce por la propia intervención voluntaria del autor (desistimiento, artículo 18 del Código Penal) o por circunstancias externas. 
Aspectos importantes de la tentativa inidónea están referidos al inicio de la fase ejecutiva y a la imposibilidad absoluta de realizar el delito, debido a la inidoneidad del medio o del objeto (artículo 17 del Código Penal de 1991). La inidoneidad absoluta del objeto puede presentarse por razones fácticas o jurídicas. Así, inidoneidad fáctica absoluta del objeto: tentativa de aborto en una mujer no embarazada; inidoneidad jurídica absoluta del objeto: tentativa de hurto cuando se desconoce el consentimiento del propietario. La inidoneidad absoluta del medio.- Entendemos que el texto legal cuando se refiere al "medio" se refiere tanto a los instrumentos como a las conductas del agente. La exigencia legal de la imposibilidad absoluta, hace descartar los casos en los que el medio o el objeto eran relativamente inidóneos. En estos casos, será recomendable tipificar la conducta en el artículo 16 del Código Penal.

Desistimiento en tentativa inacabada (artículo 18 del Código Penal).Se presenta en la tentativa inacabada, cuando iniciado el proceso de ejecución el autor lo abandona voluntariamente.

Según su plan de acción, él considera que no ha hecho lo que tenía que hacer para consumar el delito y decide voluntariamente interrumpir la ejecución. Ejemplo: El ladrón que, según su plan personal, ingresa a una casa a sustraer un valioso jarrón y en el momento en el que pretendía tomarlo se desiste y se retira del lugar. Nuestro Código Penal declara que esta tentativa no es punible.

Requisitos.- El desistimiento requiere:

a) Abstenerse de continuar con la ejecución del proceso tendente a la consumación del delito;

b) Voluntariedad: el artículo 18 del Código Penal exige la voluntariedad del desistimiento. Hay algunos autores que alcanzan a diferenciar la "espontaneidad" de la "voluntariedad". El Código Penal de 1924 hacía referencia a la "espontaneidad", mientras que el actual Código adopta el término "voluntariamente", lo que consideramos positivo, pues en el caso del sujeto que interrumpe la ejecución por sugerencia de la víctima o de un tercero, la exigencia de la "espontaneidad" excluiría el desistimiento. Ejemplo: el violador que desiste porque la joven le promete satisfacer voluntariamente su deseo en otra oportunidad. En la doctrina dominante se utiliza el término "voluntariedad".

Abandono definitivo de la ejecución del delito.- Existen dos posicio- 
nes: la primera sostiene que es definitivo el desistimiento cuando el sujeto abandona su propósito original (ejecución concreta iniciada) aunque piense en el futuro intentarla de nuevo. La segunda exige que el autor abandone definitivamente, renuncie completamente a la ejecución, sin reservas. Nos inclinamos por la primera solución.

El desistimiento es una causa personal de cancelación de la punibilidad, a favor del sujeto que se ha desistido en forma eficaz. El desistimiento queda impune, no así los actos practicados que constituyan por sí mismos delitos (artículo 18 del Código Penal).

Interrupción exterior en tentativa inacabada.- La interrupción exterior se produce en el momento en que el agente ha comenzado la ejecución del delito. Ejemplo: en el delito de hurto, la ejecución es interrumpida accidentalmente en el momento de la sustracción debido al funcionamiento automático de la alarma, la intervención de la policía, u otras circunstancias. Las posibilidades de interrupción accidentales son innumerables. Ejemplo: en el caso del hijo que ofrece un postre envenenado a su padre, a quien pretende matar (parricidio, artículo 107 del Código Penal), pueden ser diversas las circunstancias de interrupción: el padre conoce las intenciones del hijo y evita tomar el postre; interrumpe la ejecución una tercera persona que conocía el plan del autor, etc.

El desistimiento en tentativa acabada se presenta cuando el sujeto de acuerdo a su plan ya realizó todos los actos necesarios para la producción del resultado y desarrolla una nueva actividad para impedirlo. Se pueden identificar algunas condiciones: actividad positiva del agente, voluntariedad del desistimiento, debe ser definitivo $y$, finalmente, debe ser eficaz.

\section{Casos de inimputabilidad}

Anomalía psíquica.- También llamada perturbación psíquica morbosa, se explica por la presencia de procesos psíquicos patológicos corporales, producidos tanto en el ámbito emocional como en el intelectual, que escapan al marco de un contexto vivencial y responden a una lesión del cerebro: psicosis traumáticas, psicosis tóxicamente condicionadas, psicosis infecciosas, y otras (22).

(22) Jescheck II, pág. 601. Stratenwerth 1982, pág. 109. 
Para la ciencia española se trata del trastorno mental permanente o enajenación, "que implica un proceso morboso o patológico, de carácter permanente y que produce una alteración absoluta de las facultades mentales" (23). Dentro de estos trastornos mentales se encuentran las psicosis (esquizofrenias, paranoia, psicosis maniaco-depresiva), la epilepsia, la oligofrenia (ideocia, imbecilidad, debilidad mental).

Es precisamente a estas anomalías a las que se refiere el Código Penal peruano de 1991. Nos parece que el término "anomalía psíquica" es más apropiado que el de "enfermedad mental". La anomalía psíquica es un caso de inimputabilidad. La inimputabilidad puede ser consecuencia no sólo de ciertos estados patológicos durables (anomalía psíquica) sino igualmente de ciertos estados anormales que son pasajeros (24). El artículo 20, inciso 1, declara que está exento de responsabilidad penal el que por una "grave alteración de la conciencia [...] no posea la facultad de comprender el carácter delictuoso de su acto o para determinarse según esta comprensión".

Grave alteración de la percepción.- Se fundamenta en el criterio biológico natural, que evalúa las dimensiones biológicas de los sentidos. En un primer momento se limitó al habla y a la audición; ahora se admite la alteración de todos los sentidos.

Está criticada la alteración de la percepción en el sentido de "realidad inequívoca" pues cada uno tiene su propia realidad. Lo que interesa es una realidad valorativa, que puede ser jurídica, pero también esto es insuficiente (25).

Admitido que esta alteración de la percepción se refiere a todos los sentidos, ésta puede tener su origen en el nacimiento, o luego en la infancia, $y$ hace que el individuo tenga una percepción parcial de la realidad (26).

Por nuestra parte consideramos que la inimputabilidad de los menores

(23)Bustos 1989, pág. 341. Vid. Mir 1985, pág. 489, 491. Gómez Benites 1987, págs. 458-464.

(24) Logoz 1976, pág. 72. Cfr. Stratenwerth 1982, pág. 71.

(25) Bustos, pág. 545.

(26) Cfr. Carbonell-Gómez-Mengual 1987, pág. 59. 
de edad se fundamenta con las razones de seguridad jurídica (27). Pero también reconocemos que un menor de edad puede comprender el carácter ilícito de su acto y adecuar su conducta de acuerdo con esa comprensión. En este último sentido político-criminal resulta más adecuado el tratamiento educativo específicn que el puro castigo.

Nuestro Código considera que está exento de responsabilidad penal el menor de 18 años, encontrándose el menor sujeto a las disposiciones tutelares del Código de Menores.

Causas de justificación, atipicidad, inculpabilidad

Legítima defensa.- Está prevista en el artículo 20 inciso 3 del Código Penal y puede entenderse como la defensa necesaria ante una agresión ilegítima no provocada suficientemente.

\section{Requisitos:}

- Agresión ilegítima.

- Necesidad racional del medio empleado para impedirla o repelerla.

- Falta de provocación suficiente de quien hace la defensa.

Se trata de una conducta humana agresiva e ilegítima que tiende a lesionar o poner en peligro bienes jurídicos protegidos.

La agresión no es sólo un obrar activo (comisión) sino que tambien puede admitirse por omisión propia.

Cuando nuestro Código Penal expresa que la defensa se hace para "impedir" o "repeler" la agresión, se está refiriendo a que la agresión puede ser inminente o actual.

La agresión es actual (repeler) mientras se está desarrollando. Este es el único momento en que se puede repeler. La agresión seguirá siendo actual hasta que no se produzca la consumación. La agresión desaparece cuando el delito está consumado o agotado.

(27) Cfr. Mir, pág. 516. 
La ilegitimidad de la agresión.- La agresión ilegítima es agresión antijurídica. El carácter antijurídico de la agresión tiene que valorarse en relación a todo el ordenamiento jurídico.

En este sentido, cualquier bien jurídico puede ser agredido. En consecuencia, no es necesario que la agresión sea típica, es decir, que constituya un delito. Si bien es cierto que la agresión es generalmente un delito, eso no significa que siempre lo sea.

No es suficiente que el que se defienda imagine la agresión. Para la legítima defensa, la agresión debe ser real. Si la agresión es imaginada por quien se defiende estaremos ante un caso de legítima defensa putativa. Creemos que el tratamiento que corresponde es el del error de prohibición vencible o invencible, de acuerdo a las circunstancias (art. 14, segundo parrafo, del Codigo Penal).

Necesidad de la defensa ("necesidad racional del medio empleado para impedirla o repelerla"). Defensa es aquella conducta dirigida a rechazar la agresión.

La defensa es necesaria si la acción del agredido era la menos dañosa de cuantas estaban a su disposición para rechazar la agresión en la situación concreta.

Es diferente la "racionalidad" de la "proporcionalidad" (término que no usa nuestro texto legal). Hablar de "proporcionalidad" estaría en función a decidir sobre la probable jerarquía de bienes jurídicos en conflicto y la lesión objetiva a los mismos. Tal situación no se presenta en la legítima defensa.

La racionalidad de la defensa no se puede determinar en forma abstracta, objetiva y general sino que dependerá de la situación concreta y de las circunstancias de ella.

Falta de provocación suficiente.- El sujeto que se defiende no debe haber provocado la agresión. Ejemplo: el que insultó de manera grave a otro, no puede alegar legítima defensa si es agredido levemente por éste.

La provocación es suficiente "cuando hace previsible una agresión, sin 
que a este efecto puedan tomarse en cuenta las características personales antisociales del agresor" (28).

Elemento subjetivo de la legítima defensa.- Sólo quien actúa con conocimiento de la situación de agresión y con la voluntad de defenderse (animus defendendi) actúa amparado por la causa de justificación de la legítima defensa, incluso si concurren otros fines con el de defensa (venganza, odio, etc.)

Estado de necesidad como causa de justificación

El estado de necesidad es un "estado de peligro actual para legítimos intereses que únicamente puede conjurarse mediante la lesión de los intereses legítimos de otra persona (29). Esta es la definición más usual; sin embargo, es un concepto muy amplio en el que cabrían otras causas de justificación, por ejemplo la legítima defensa.

Situación de peligro.- Es el primer requisito del estado de necesidad justificante. Esta situación de peligro puede ser actual o inminente y además real, como expresamos al desarrollar la legítima defensa. El peligro no deja de ser actual por el hecho de ser permanente o continuo.

Cualquier bien jurídico puede encontrarse en situación de peligro. En este sentido, el artículo 20 inciso 4 del Código Penal de 1991 se refiere a "la vida, integridad corporal, la libertad u otro bien jurídico...".

El peligro será inminente cuando la afectación al bien jurídico sea de muy alta probabilidad o segura.

Acción necesaria.- La acción de defensa debe ser necesaria, es decir, "para que concurra un estado de necesidad es preciso que no haya un modo menos lesivo de evitar el mal que amenaza".

Elemento subjetivo.- El estado de necesidad también requiere de un

(28) Zaffaroni 1987, pág. 493. Vid. Tratado III, pág. 608.

(29) Jescheck I, pág. 483. 
elemento subjetivo: el conocimiento de la situación de peligro y la voluntad de defensa para evitar el mal grave. Además, este elemento subjetivo puede estar acompañado de otras intenciones o estados anímicos.

Estado de necesidad como causa de inculpabilidad.- Se trata de los casos en los que los bienes protegidos o los lesionados son iguales. Así, el ejemplo de los dos náufragos sostenidos en una tabla, la que sólo puede soportar el peso de uno de ellos y como consecuencia el otro mata para sobrevivir (Welzel).

Para que esta causal de inculpabilidad se aplique es necesario: a) Los bienes jurídicos que se encuentran protegidos son la vida, el cuerpo y la libertad. $b$ ) El peligro debe ser actual; se trata de una alta probabilidad de afectación al bien juridico. c) La gravedad del resultado de la acción de salvamento respecto del interés jurídicamente protegido, no debe estar en una relación desproporcionada frente a la magnitud del peligro evitado. d) Debe ser la única posibilidad de salvación.

El "miedo" es un estado psicológico personalísimo que obedece a estímulos o causas no patológicas (30). El miedo no debe entenderse como terror (31), pues tal privación de facultades en el autor podría originar un caso de inimputabilidad. El miedo al que nos referimos, aun afectando psíquicamente al autor, le deja una opción o posibilidad de actuación (32). No siendo el miedo de origen patológico, debe ser producido por estímulos externos al agente.

El miedo debe ser insuperable, es decir, no dejar otra posibilidad normal al sujeto en el momento de actuar (33).

Obrar por disposición de la ley supone el cumplimiento de un deber que la ley ordena. Ejemplo: deber de testificar, deber de denunciar. Es diferente al obrar por orden obligatoria pues el deber no surge de la subordinación con el superior, sino en relación al orden juridico.

(30) Gímez Benitez, 1987, pág. 431.

(31) Mir Puig, 1985, pág. 527.

(32) Muñoz Conde 1984, pág. 166.

(33) Bustos 1984, pág. 354. 
Estos casos de obligación específica de actuar, conforme a su función o profesión, incluyen la actividad de médicos, funcionarios, policías, etc. y plantea dificultades hermenéuticas, pues resulta necesario conocer el contenido de las regulaciones administrativas de cada función o profesión. Así, el problema puede surgir en el supuesto de disposiciones confusas. "Una reglamentación administrativa no puede justificar abusos del poder, arbitrariedades, etc. de las autoridades. Sin embargo, sucede esto muchas veces cuando, por medio de conceptos jurídicos indeterminados y de cláusulas que dejan amplio espacio a la discrecionalidad, se deja al arbitrio de la autoridad la decisión para valorar los presupuestos objetivos o los límites jurídicos de su actuación" (34).

El uso de violencia por parte de la autoridad al momento de cumplir con su deber de función o profesión, supone un principio básico que es el de la menor lesividad posible, es decir, el empleo de la fuerza racionalmente imprescindible para el cumplimiento de la obligación.

Ejercicio legítimo de un derecho: El derogado Código Penal de 1924 se refería al "acto permitido por la ley" (artículo 85, inciso 4). El nuevo C6́digo Penal de 1991 se refiere al "ejercicio legítimo de un derecho" (art 20 inc. 8 del Código Penal).

Se trata entonces de ubicar aquellas autorizaciones o permisos especificos y ciertamente particulares para la realización de un tipo. Ejemplo: derecho de corrección (artículo 432, inciso 3, del Código Civil).

Otros ejemplos pueden ser: el derecho de huelga (artículo 55 de la Constitución) en relación al tipo de lo injusto de la usurpación (artículo 202 del Código Penal), derecho de libertad de información, opinión, expresión y difusión del pensamiento (artículo 2, inciso 4 de la Constitución) en relación a la difamación (artículo 132 del Código Penal), etc.

Obediencia jerárquica.- En cuanto a su naturaleza jurídica existen discrepancias entre los que afirman que se trata de una causa de justificación y los que creen que es una causa de no exigibilidad (inculpabilidad). Creemos

(34) Muñoz 1984, pág. 116. 
que esta última es la posición más aceptable. Algunos autores aceptan la posibilidad de obediencia jerárquica por atipicidad cuando de lo que se trata es de actuar en cumplimiento de un deber (artículo 20, inciso 8, del Código Penal) (35).

Se diferencia entre el acuerdo y el consentimiento.

El acuerdo (Einverständnis) excluye la tipicidad de la conducta en los casos en los que el tipo legal respectivo presupone un obrar contra o sin la voluntad del afectado. Ejemplo: el tipo legal del aborto (artículo 116 del Código Penal) sanciona al que hace abortar a una mujer sin su consentimiento. En este supuesto, el acuerdo elimina la tipicidad de la conducta.

El consentimiento (Einwilligung) elimina la antijuricidad de la conducta en los casos en "que el consentimiento de la víctima tiene lugar en hechos que atacan un bien jurídico del que puede disponer su titular, pero cuya lesión no desaparece por virtud del consentimiento" (36). El consentimiento es en este caso una causa de justificación. Ejemplo: el que daña, destruye o inutiliza una cosa con el consentimiento del propietario (daños, artículo 205 del Código Penal).

El consentimiento no es de eficacia general. No se aceptará en el caso de delitos contra la colectividad. El consentimiento podrá aceptarse en delitos contra los particulares, siempre que sean exclusivamente privados.

En otros casos resulta muy discutible la eficacia del consentimiento, particularmente en delitos que protegen intereses públicos junto a intereses privados. Esto ocurre por ejemplo en delitos contra la vida, en los que el consentimiento es ineficaz.

Autoría y participación

Autoría.- Para nosotros el concepto de autor es óntico-ontológico y

(35)Cf. Bustos 1989, pág. 222. Zaffaroni 1987, pág. 562. Fernández C. 1989, pág. 340.

(36) Mir Puig 1985, pág. 447. 
para precisarlo se requieren características generales y especiales. En todo caso, el artículo 23 del Código Penal de 1991 es una disposición legal que se asienta en el concepto óntico-ontológico de autor.

El dominio final sobre el hecho constituye la característica general de la autoría. Autor es el que tiene el dominio del hecho, es decir, aquel sujeto que tiene un poder de conducción de todos los acontecimientos de forma tal que le es posible encauzarlo hacia el fin determinado.

Autoría mediata.- Autor mediato es el sujeto que se sirve del actuar de un intermediario, pero sólo él tiene el dominio del hecho.

Casos de autoría mediata.- Antes de desarrollar los diversos casos de autoría mediata es conveniente indicar que no se acepta la autoría mediata en los supuestos en los que falta la acción del intermediario, particularmente si se utiliza sobre él fuerza física irresistible. En este caso consideramos que se trata de un supuesto de autoría directa, pues la utilización meramente material de un hombre no se distingue del empleo de otro instrumento no humano. Ejemplo: el sujeto que empuja a otro con el propósito que caiga pesadamente y lesione a un tercero, es responsable por autoria directa.

Adoptamos igual solución en los casos en que el sujeto utilice como instrumentos a los animales o máquinas para cometer la infracción.

Los diversos casos de autoría mediata pueden ser clasificados de la siguiente manera:

1. Ejecutor que actúa sin realizar lo injusto:

- Actúa sin realizar el tipo objetivo.

- Actúa sin realizar el tipo subjetivo.

- Actúa justificado.

2. Ejecutor que actúa sin culpabilidad:

- Ejecutor inimputable.

- Ejecutor en error de prohibición.

- Ejecutor inexigible.

3. Problemática especial: Ejecutor que actúa dentro de un aparato poder, que para nosotros plantea la figura de la coautoria (37).

(37) Vid. Villavicencio 1990, págs. 208, 209. 
Coautores son los que toman parte en la ejecución del delito, en codominio del hecho (dominio funcional del hecho). Ejemplo: los homicidas, de los que uno inhabilita a la víctima de los brazos, mientras los otros le infieren heridas punzo-cortantes.

Para determinar el co-dominio del hecho, que fundamenta la coautoría, se requieren dos condiciones: la decisión común y la realización en común (división del trabajo).

La instigación, al lado de la complicidad (primaria o secundaria) constituye una forma de participación en sentido estricto (artículo 24 del Código Penal), siendo a su vez una extensión típica pues amplía los tipos de la parte especial para abarcar la conducta de quien dolosamente determinare a otro a cometer el hecho punible. La tipicidad de la conducta del instigador se deduce de la aplicación de la regla del artículo 24 del Código Penal a un tipo de la parte especial.

Podemos definir la instigación como aquella conducta activa que dolosamente hace surgir en el autor la decisión, la resolución, de realizar un delito doloso concreto.

Instigar es decidir a otro a la ejecución del hecho punible, lo que significa que el instigado ha formado su voluntad de realización del hecho como consecuencia directa de la acción del instigador. De esto se deduce que no puede ser objeto idóneo de la instigación, el que ya estaba decidido a cometer ei hecho concreto (omnimodo facturus).

Cómplice es el que dolosamente colabora con otro para la realización de un delito doloso. La complicidad no sólo implica un aporte material sino que también puede consistir en un apoyo psicológico. Este aporte psicológico otorgado por el cómplice no debe ser el que haga surgir en el autor la decisión a la realización del hecho, pues en ese caso estaremos antẹ una instigación. Para que se presente la complicidad intelectual, la influencia piscológica debe significar un apoyo a la decisión ya tomada por el autor.

Se diferencia entre complicidad primaria y secundaria. El cómplice primario es el que otorga un aporte sin el cual no se hubiera podido cometer cl delito. El Código Penal (art. 25 primer párrafo) precisa que será reprimido con la pena prevista para el autor. 
La complicidad secundaria se presenta cuando el aporte no es indispensable para la realización del delito. El segundo parrafo del art. 25 del Código Penal señala que a estos cómplices se les disminuirá prudencialmente la pena.

Las consecuencias de la accesoriedad limitada en la participación están indicadas en el art. 26 del nuevo Código Penal.

Actuación en nombre de otro. No existe dificultad para estimar penalmente responsables a las personas físicas que actúan como órganos de representación en aquellos casos en los que el tipo correspondiente no exige especial cualidad para ser sujeto activo del delito. El problema se presenta en los supuestos de delitos especiales, en aquellos casos en que la calidad especial concurre en la persona jurídica pero no en la persona física que actúa como órgano o representante de dicha entidad. El art. 27 del Código Penal pretende resolver este problema al autorizar la traslación de una característica personal de autoría a quien no la tiene (38).

(38) Cf. Octavio de Toledo y Ubieto, Emilio: "Las actuaciones en nombre de otro", en Anuario de derecho penal y ciencias penales, Madrid, t. XXXVII, 1984, pág. 36. 
BIBLIOGRAFIA

BATISTA, Nilo

1984 Temas de Direito penal. Editora Liber Juris, Rio de Janeiro.

BACIGALUPO, Enrique

1983 Delitos impropios de omisión. $2^{\mathbf{a}}$ edición, Temis, Bogotá.

1987 Derecho penal. Parte general. Hammurabi, Buenos Aires.

BERDUGO GOMEZ DE LA TORRE, Ignacio

1984 Revisión del contenido del bien juridico honor en Anuario de derecho penal y ciencias penales, p. 305 ss.

BRAMONT ARIAS, Luis

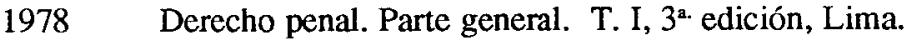

BRANDT, Hans

1987 Justicia popular. Lima

BUSTOS R., Juan

1989 Manual de derecho penal español. Parte general. Ariel, Barcelona.

CEREZO MIR, José

1988 Curso de derecho penal español. Parte general I, Tecnos, Madrid.

1990 Curso de derecho penal español. Parte general. T. II, Teoría jurídica del delito 2; Madrid.

CARBONELL M., J. C. - GOMEZ COLOMER, J. L. - MENGUAL, J. B. 1987 Enfermedad mental y delito. Civitas, Madrid. 
FERNANDEZ CARRASQUILLA, Juan

1989 Derecho penal fundamental. Vols. I, II, Temis, Bogotá.

FRAGOSO, Heleno C.

1985 Liçoes de direito penal, A nova Parte Geral, $9^{\mathrm{a}}$ ediçáo.

Forense, Rio de Janeiro.

GOESSEL, Karl Heinz

1984 Dos estudios sobre la teoría del delito. Temis, Bogotá.

GOMEZ BENITEZ, José Manuel

1987 Teoría jurídica del delito. Derecho penal, parte general.

Civitas, Madrid.

HURTADO POZO, José

1987 Manual de derecho penal. Parte general. $2^{\mathbf{a}}$ edición Eddili, Lima.

HUERTA TOCILDO, Susana

1982 Concepto ontológico o concepto normativo de omisión en Cuadernos de Política Criminal № 17, Edersa, Madrid.

JESCHECK, Hans-H

1981 Tratado de derecho penal, parte general. 2 volúmenes, trad. Mir Puig-Muñoz Conde, Bosch, Barcelona.

JESUS, Damasio E. de

1985 Direito penal. Parte geral. $1^{9}$ volume $10^{2}$ ediçáo, Saraiva, Sáo Paulo.

LOGOZ, Paul

1976 Commentaire du Code Pénal Suisse. Partie Générale. Delachaux \& Niestlé, Neuchatel, Paris.

MANTOVANNI, Ferrando

1979 Diritto penale. Parte generale. Cedam, Padova, Italia.

1988 Diritto penale. Parte generale. Seconda edizione, Cedam, Padova, Italia. 
MIRABETE, Julio Fabbrini

1988 Manual de direito penal. Parte geral. Vol. 1, Edt. Atlas S. A. Sáo Paulo.

MIR PUIG, Santiago

1983 Lecciones de derecho penal. Teoría del delito. Barcelona.

1990 Derecho penal. Parte general. $3^{\text {a }}$ edición, Barcelona.

MUÑOZ CONDE, Francisco

1984 Teoría general del delito. Temis, Bogotá.

PEÑA C., Raúl

1983 Tratado de derecho penal. Parte general VI. $3^{\mathbf{a}}$ ed., Lima.

PEREZ PINZON, Alvaro

1989 Introducción al derecho penal. Señal Editora, Medellín, Colombia.

PIERANGELLI, José $\mathrm{H}$.

1989 O Consentimiento do ofendido na Teoría do delito. Ed. Revista dos Tribunais, Sáo Paulo.

PRADO S., Víctor

1990 Derecho penal y política. Eddili, Lima.

QUINTERO OLIVARES, G.

1989 Derecho penal. Parte general, $2^{2}$ edición, Madrid.

ROXIN Claus

1976 Problemas básicos de derecho penal. Trad. Manuel Luzón P., Reus S.A., Madrid.

ROXIN, Claus - ARTZ, G. - TIEDEMANN, Klaus

1989 Introducción al derecho penal y al derecho penal procesal. Ariel, Barcelona.

RODULPHI, Hans J.

1975 Los diferentes aspectos del concepto del bien jurídico en Nuevo pensamiento penal, Año IV, № 7 . 
STRATENWERTH, G.

1982 Derecho penal. Parte general. Trad. G. Romero, Edersa, Madrid.

TOLEDO, Francisco de Assis

1987 Principios básicos de direito penal. $3^{\text {a }}$ ediçáo, Saraiva, Sáo Paulo.

TOLEDO Y UBIETO, Octavio de

1984 Las actuaciones en nombre de otro en Anuario de derecho penal y ciencias penales, pag. 36 ss.

VELASQUEZ V., Fernando

1989 Normas rectoras del proyecto de código penal peruano en Anuario de derecho penal, № 1, Lima.

VILLAVICENCIO T. Felipe

1983 Delitos contra la seguridad pública. Delito de terrorismo, $2^{a}$ edición, Sesator, Lima.

1989 Mecanismos naturales de regulación social en comunidades andinas y amazónicas peruanas en Criminalia. Academia Mexicana de Ciencias Penales, págs. 90 ss, México D.F.

1990 Lecciones de derecho penal. Parte General. Lima.

1991 Lecciones de derecho penal. Parte Especial 1, Delitos de homicidio. Lima.

WELZEL, Hans

1976 Derecho penal alemán. Parte general. Trad. Bustos-Yañez, Ed. Jurídica de Chile, Santiago.

ZAFFARONI, Eugenio R.

1980 Tratado de derecho penal. Parte general, t. I.

Ediar, Buenos Aires.

1981 Tratado de derecho penal. Parte general, tomos II y III. Ediar, Buenos Aires.

1982 Tratado de derecho penal. Parte General, t. IV. Ediar, Buenos Aires.

1983 Tratado de derecho penal. Parte General, t. V. Ediar, Buenos Aires. 
ZIELINSKI, Diethart

1990 Disvalor de acción y disvalor de resultado en el concepto de ilícito. Trd. Sancinetti. Hammurabi, Buenos. Aires. 